\title{
Treatment of Anemia with Darbepoetin Alfa in Systolic Heart Failure
}

\author{
Karl Swedberg, M.D., Ph.D., James B. Young, M.D., Inder S. Anand, M.D., \\ Sunfa Cheng, M.D., Akshay S. Desai, M.D., Rafael Diaz, M.D., \\ Aldo P. Maggioni, M.D., John J.V. McMurray, M.D., \\ Christopher O'Connor, M.D., Marc A. Pfeffer, M.D., Ph.D., \\ Scott D. Solomon, M.D., Yan Sun, M.S., Michal Tendera, M.D., \\ and DirkJ. van Veldhuisen, M.D., Ph.D., \\ for the RED-HF Committees and Investigators*
}

A BSTRACT

From the Department of Molecular and Clinical Medicine, Sahlgrenska Academy, University of Gothenburg, Gothenburg, Sweden (K.S.); the Department of Medicine, Endocrinology and Metabolism Institute, Cleveland Clinic, Cleveland (J.B.Y.) University of Minnesota Medical School and VA Medical Center, Minneapolis (I.S.A.); Amgen, Thousands Oaks, CA (S.C., Y.S.); the Cardiovascular Division, Brigham and Women's Hospital, Boston (A.S.D., M.A.P., S.D.S.); Estudios Clínicos Latinoamerica, Rosario, Argentina (R.D.); Italian Association of Hospital Cardiologists Research Center, Florence, Italy (A.P.M.); British Heart Foundation Glasgow Cardiovascular Research Centre, University of Glasgow, Glasgow, United Kingdom (J.J.V.M.); Duke University Medical Center, Durham, NC (C.O.); the Division of Cardiology, Medical University of Silesia, Katowice, Poland (M.T.); and University Medical Center Groningen, University of Groningen, Groningen, the Netherlands (D.J.V.). Address reprint requests to Dr. Swedberg at the Department of Medicine, Sahlgrenska University Hospital/Östra, 41645 Göteborg, Sweden, or at karl.swedberg@gu.se.

* Investigators in the Reduction of Events by Darbepoetin Alfa in Heart Failure (RED-HF) trial are listed in the Supplementary Appendix, available at NEJM.org.

This article was published on March 10, 2013, at NEJM.org.

N Engl J Med 2013;368:1210-9.

DOI: 10.1056/NEJMoal214865

Copyright @ 2013 Massachusetts Medical Society.

\section{BACKGROUND}

Patients with systolic heart failure and anemia have worse symptoms, functional capacity, and outcomes than those without anemia. We evaluated the effects of darbepoetin alfa on clinical outcomes in patients with systolic heart failure and anemia.

\section{METHODS}

In this randomized, double-blind trial, we assigned 2278 patients with systolic heart failure and mild-to-moderate anemia (hemoglobin level, 9.0 to $12.0 \mathrm{~g}$ per deciliter) to receive either darbepoetin alfa (to achieve a hemoglobin target of $13 \mathrm{~g}$ per deciliter) or placebo. The primary outcome was a composite of death from any cause or hospitalization for worsening heart failure.

\section{RESULTS}

The primary outcome occurred in 576 of 1136 patients (50.7\%) in the darbepoetin alfa group and 565 of 1142 patients (49.5\%) in the placebo group (hazard ratio in the darbepoetin alfa group, $1.01 ; 95 \%$ confidence interval, 0.90 to $1.13 ; \mathrm{P}=0.87$ ). There was no significant between-group difference in any of the secondary outcomes. The neutral effect of darbepoetin alfa was consistent across all prespecified subgroups. Fatal or nonfatal stroke occurred in 42 patients (3.7\%) in the darbepoetin alfa group and 31 patients $(2.7 \%)$ in the placebo group $(\mathrm{P}=0.23)$. Thromboembolic adverse events were reported in 153 patients (13.5\%) in the darbepoetin alfa group and 114 patients $(10.0 \%)$ in the placebo group $(\mathrm{P}=0.01)$. Cancer-related adverse events were similar in the two study groups.

\section{CONCLUSIONS}

Treatment with darbepoetin alfa did not improve clinical outcomes in patients with systolic heart failure and mild-to-moderate anemia. Our findings do not support the use of darbepoetin alfa in these patients. (Funded by Amgen; RED-HF ClinicalTrials .gov number, NCT00358215.) 
NEMIA IS COMMON IN PATIENTS WITH heart failure, and patients with both heart failure and anemia have a lower functional capacity, worse quality of life, and higher rates of hospitalization and death ${ }^{1-3}$ than those without anemia. ${ }^{4,5}$ The cause of anemia in patients with heart failure is often unknown but may be related to an absolute or relative deficiency of, or resistance to, erythropoietin. Anemia in such patients is associated with impaired renal function, inflammation, and use of renin-angiotensin system blockers. ${ }^{6,7}$

Small studies have suggested that increasing the hemoglobin level with the use of an erythropoiesis-stimulating agent (ESA) may improve functional capacity ${ }^{8-13}$ and reduce hospitalization in patients with heart failure and anemia, but the evidence is not robust. ${ }^{14,15}$ Furthermore, ESAs have not improved cardiovascular outcomes in patients with chronic kidney disease who had anemia, with or without diabetes, and treatment aimed at a high hemoglobin target has increased the risk of atherothrombotic events. ${ }^{16-18}$ The aim of our study, the Reduction of Events by Darbepoetin Alfa in Heart Failure (RED-HF) trial, was to determine whether treatment with darbepoetin alfa improves clinical outcomes in patients with chronic systolic heart failure and anemia that is not due to iron deficiency.

\section{METHODS}

\section{STUDY DESIGN AND OVERSIGHT}

The study design has been reported previously. ${ }^{19}$ The executive committee and steering committee designed and oversaw the conduct of the trial, including data analysis, in collaboration with representatives of the sponsor (Amgen). The ethics committee at each study center approved the trial design. Data were collected and managed by the sponsor. The University of Wisconsin Statistical Data Analysis Center (SDAC) prepared unblinded reports for the independent data and safety monitoring committee, which met approximately every 3 months to oversee patient safety. The trial results were analyzed by the sponsor according to a predefined statistical analysis plan, and the analyses were replicated by SDAC. The manuscript was prepared by an academic publications committee, whose members had unrestricted access to the data, and was subsequently revised by all the authors. All the authors participated in the decision to submit the manuscript for publication and assume responsibility for the accuracy and completeness of the data, as well as for the fidelity of this report to the trial protocol, which is available with the full text of this article at NEJM.org.

\section{STUDY PATIENTS}

Patients were eligible for the study if they had New York Heart Association (NYHA) functional class II, III, or IV heart failure; a left ventricular ejection fraction of $40 \%$ or less; and a hemoglobin level of 9.0 to $12.0 \mathrm{~g}$ per deciliter and if they were receiving guideline-recommended heart-failure therapy. Major exclusion criteria were a transferrin saturation of less than $15 \%$, evidence of bleeding or other correctable causes of anemia, a serum creatinine level of more than $3 \mathrm{mg}$ per deciliter (265 $\mu \mathrm{mol}$ per liter), and a blood pressure of more than 160/100 mm Hg. All patients provided written informed consent.

\section{STUDY PROCEDURES}

Patients were randomly assigned in a 1:1 ratio to receive either darbepoetin alfa or placebo. Randomization was stratified according to region and whether patients were receiving therapy with an implantable cardioverter-defibrillator, cardiac resynchronization, or both.

Doses of darbepoetin alfa and placebo were identical in appearance and packaging. The study drug was administered subcutaneously, with doses adjusted according to hemoglobin level, which was measured in a blinded fashion. Patients in the darbepoetin alfa group received a starting dose of $0.75 \mu \mathrm{g}$ per kilogram of body weight once every 2 weeks until a hemoglobin level of $13.0 \mathrm{~g}$ per deciliter was reached on two consecutive visits. Thereafter, patients received monthly injections, according to an algorithm ${ }^{19}$ that was designed to maintain a hemoglobin level of $13.0 \mathrm{~g}$ per deciliter (but not exceeding $14.5 \mathrm{~g}$ per deciliter) (Table S1 in the Supplementary Appendix, available at NEJM.org). Patients in the placebo group received dose adjustments to mimic those in the darbepoetin alfa group. Dose assignments in the two groups were performed by an interactive voice-response system.

Blood iron indexes were assessed every 3 months during the trial. If the transferrin saturation fell to less than $20 \%$ at any time during the study, oral (and, if necessary, intravenous) iron was admin- 
istered as tolerated, according to a specified algorithm (for details, see the Supplementary Appendix). Use of supplemental iron was recorded.

\section{STUDY OUTCOMES}

The primary outcome was a composite of death from any cause or first hospitalization for worsening heart failure. The prespecified adjudicated secondary outcomes were death from any cause and the composite of death from cardiovascular causes or first hospitalization for worsening heart failure. Additional secondary outcomes were the change from baseline to 6 months in the Overall Summary Score and Symptom Frequency Score on the Kansas City Cardiomyopathy Questionnaire (KCCQ). ${ }^{20}$ The KCCQ scores range from 0 to 100 , with higher scores indicating better quality of life and fewer symptoms and a change of 5 points considered to be clinically meaningful. ${ }^{21}$ Clinical events were adjudicated according to prespecified definitions (Table S2 in the Supplementary Appendix) by members of an independent committee whose members were unaware of studygroup assignments and hemoglobin levels.

\section{STATISTICAL ANALYSIS}

We determined that the primary outcome would need to occur in approximately 1150 patients in order to detect a between-group difference of 20 percentage points (assuming an annualized event rate of $25 \%$ in the placebo group) with a power of $80 \%$ after adjustment for the attenuation of treatment effect. The overall type I error was controlled at a significance level of 0.05 . The protocol originally assumed that approximately 2600 patients would be enrolled for the accrual of 1150 events. However, because enrollment took longer than anticipated, 1150 events were expected to accrue before the enrollment target was reached, and recruitment was stopped after 2278 patients had been randomly assigned to a study group.

All patients who underwent randomization were included in analyses of the primary and secondary outcomes. We used the Kaplan-Meier approach and a two-sided stratified log-rank test to perform time-to-event analyses. Hazard ratios and $95 \%$ confidence intervals were estimated with the use of stratified Cox proportional-hazards models. We performed a secondary analysis of the primary outcome using a Cox proportionalhazards model that was adjusted for the stratifi- cation variables, as well as for baseline age, sex, NYHA functional class, hospitalization for heart failure within 6 months before randomization (yes vs. no), diabetes (yes vs. no), log serum creatinine level, ejection fraction, cause of heart failure (ischemic vs. nonischemic), body-mass index, left bundle-branch block (yes vs. no), history of atrial fibrillation or flutter (yes vs. no), and systolic blood pressure.

The consistency of the treatment effect was assessed in an as-treated analysis, which included only the outcomes that occurred on or before the date of the last dose of the study drug plus 30 days. The primary outcome was also analyzed according to age; sex; race or ethnic group; region; treatment with an implantable cardioverter-defibrillator, cardiac resynchronization therapy, or both; and estimated glomerular filtration rate (GFR). The patient-reported secondary outcomes were analyzed with the use of a mixed-effects model after adjustment for the stratification variables and the baseline KCCQ score. We used the Medical Dictionary for Regulatory Activities, version 15.1, to identify all adverse events of interest. Query search strategies were specified in the statistical analysis plan. All statistical analyses were performed with the use of SAS software, version 9.2. (Additional information on statistical methods is provided in the Supplementary Appendix.)

\section{RESULTS}

\section{PATIENTS}

From June 13, 2006, to May 4, 2012, a total of 2278 patients underwent randomization at 453 sites in 33 countries. Of these patients, 1136 were assigned to the darbepoetin alfa group and 1142 to the placebo group (Fig. S1 in the Supplementary Appendix). The study groups were balanced with respect to baseline characteristics ${ }^{22}$ (Table 1 , and Table S3 in the Supplementary Appendix). The median age was 72.0 years; $41 \%$ of the patients were women, $65 \%$ had NYHA class III or IV disease, the median left ventricular ejection fraction was $31 \%$, and the median estimated GFR was $45.7 \mathrm{ml}$ per minute per $1.73 \mathrm{~m}^{2}$ of body-surface area.

\section{STUDY-DRUG ADMINISTRATION AND FOLLOW-UP}

Five patients ( 3 in the darbepoetin alfa group and 2 in the placebo group) did not receive any doses of the study drug and were not included in the 


\begin{tabular}{|c|c|c|}
\hline Characteristic & $\begin{array}{l}\text { Darbepoetin Alfa } \\
\quad(\mathrm{N}=1136)\end{array}$ & $\begin{array}{l}\text { Placebo } \\
(\mathrm{N}=1142)\end{array}$ \\
\hline Median age (interquartile range) $-\mathrm{yr}$ & $72.0(63.0-78.0)$ & $71.0(63.0-78.0)$ \\
\hline Female sex (\%) & 40.3 & 42.6 \\
\hline \multicolumn{3}{|l|}{ Race $(\%) \dagger$} \\
\hline White & 68.8 & 67.3 \\
\hline Black & 7.8 & 9.9 \\
\hline Other & 23.4 & 22.8 \\
\hline Median body-mass index (interquartile range) $\ddagger$ & $26.1(23.3-30.0)$ & $26.3(23.4-30.2)$ \\
\hline \multicolumn{3}{|l|}{ New York Heart Association class (\%) } \\
\hline II & 32.6 & 36.9 \\
\hline III or IV & 67.4 & 63.0 \\
\hline $\begin{array}{l}\text { Median left ventricular ejection fraction (interquartile } \\
\text { range) - } \%\end{array}$ & $31.0(25.0-35.0)$ & $30.0(25.0-35.0)$ \\
\hline Median duration of heart failure (interquartile range) $-\mathrm{yr}$ & $3.8(1.3-7.5)$ & $3.5(1.2-7.7)$ \\
\hline Ischemic heart failure (\%) & 73.2 & 72.6 \\
\hline \multicolumn{3}{|l|}{ Medical history (\%) } \\
\hline Hypertension & 73.0 & 74.1 \\
\hline Diabetes & 46.3 & 46.3 \\
\hline Atrial fibrillation or flutter & 33.3 & 32.3 \\
\hline Stroke (hemorrhagic or ischemic) & 7.7 & 8.0 \\
\hline Hospitalization for heart failure within past 6 mo & 35.4 & 38.4 \\
\hline Cancer』 & 8.2 & 6.8 \\
\hline \multicolumn{3}{|l|}{ Medication (\%) } \\
\hline ACE inhibitor or ARB & 87.9 & 89.9 \\
\hline Beta-blocker & 85.4 & 84.7 \\
\hline Diuretic & 90.5 & 92.5 \\
\hline Mineralocorticoid-receptor antagonist & 43.6 & 45.8 \\
\hline \multicolumn{3}{|l|}{ Median blood pressure (interquartile range) $-\mathrm{mm} \mathrm{Hg}$} \\
\hline Systolic & $120.0(109.0-133.0)$ & $120.0(108.0-130.0)$ \\
\hline Diastolic & $70.0(60.0-80.0)$ & $70.0(60.0-78.0)$ \\
\hline Median heart rate (interquartile range) - beats/min & $72.0(64.0-80.0)$ & $71.0(64.0-80.0)$ \\
\hline \multicolumn{3}{|l|}{ Median laboratory values (interquartile range) } \\
\hline Creatinine $-\mathrm{mg} / \mathrm{dl}$ & $1.40(1.10-1.80)$ & $1.40(1.10-1.80)$ \\
\hline Estimated glomerular filtration rate $-\mathrm{ml} / \mathrm{min} / 1.73 \mathrm{~m}^{2}$ & $45.6(34.0-61.3)$ & $45.8(34.1-61.6)$ \\
\hline Hemoglobin $-\mathrm{g} / \mathrm{dl}$ & $11.15(10.55-11.60)$ & $11.20(10.65-11.65)$ \\
\hline Transferrin saturation — \% & $24.0(19.0-31.0)$ & $24.0(19.0-31.0)$ \\
\hline
\end{tabular}

* There were no significant differences between the two groups except for New York Heart Association class $(P<0.05)$.

$P$ values were not adjusted for multiple comparisons. To convert the values for creatinine to micromoles per liter, multiply by 88.4. ACE denotes angiotensin-converting enzyme, and ARB angiotensin-receptor blocker.

$\dagger$ Race was self-reported.

$T$ The body-mass index is the weight in kilograms divided by the square of the height in meters.

$\int$ Not included in this category were patients with a history of basal-cell carcinoma, squamous-cell carcinoma, or cervical intraepithelial neoplasia.

The New England Journal of Medicine 


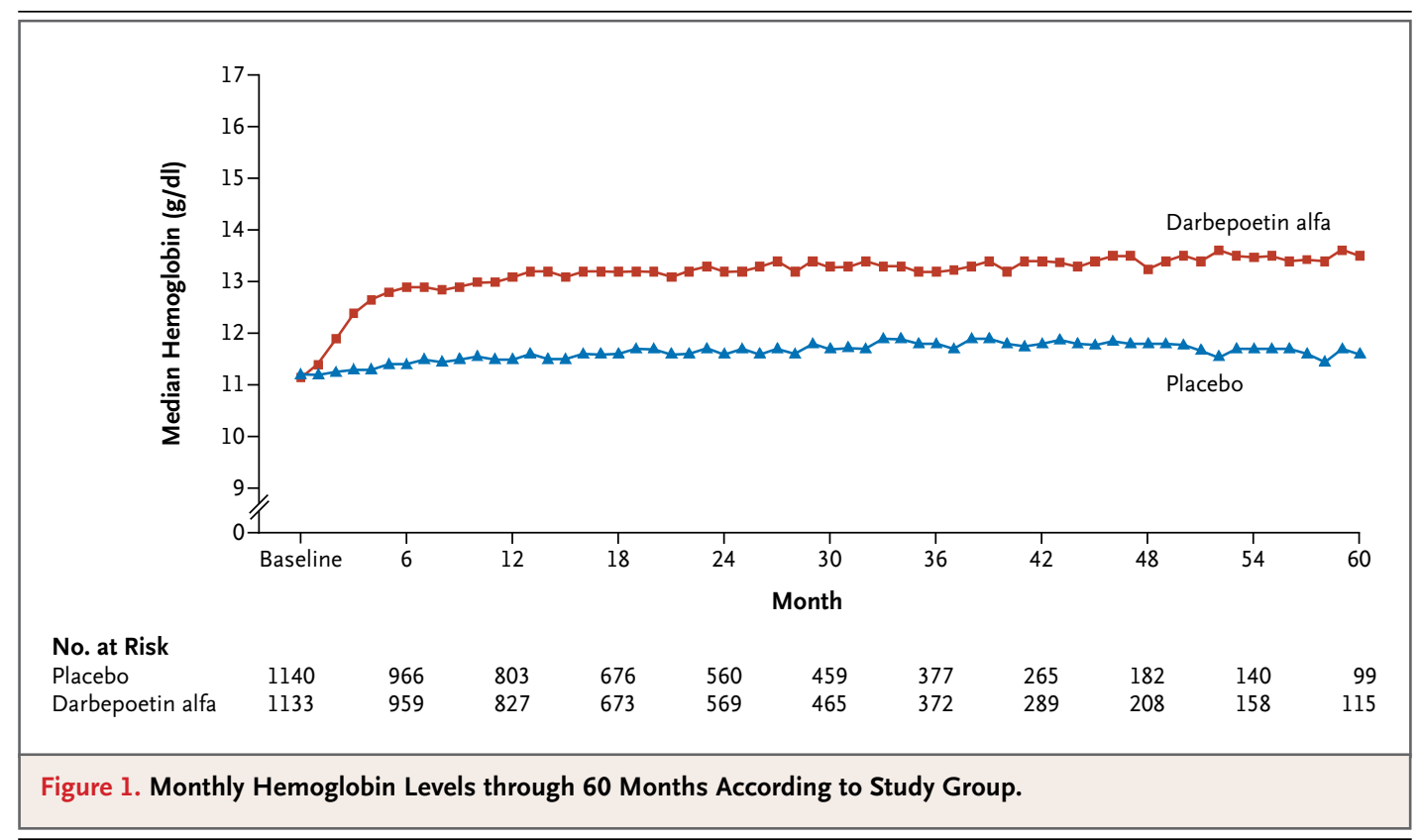

safety analysis. The study drug was discontinued for reasons other than death in 368 patients (32.4\%) in the darbepoetin alfa group and 412 patients (36.1\%) in the placebo group (Table S4 in the Supplementary Appendix).

The study was terminated on September 1, 2012, with a median follow-up of 28 months. Vital status at study termination was unknown for 13 patients $(1.1 \%)$ in the darbepoetin alfa group and $21(1.8 \%)$ in the placebo group because of loss to follow-up or withdrawal of consent (Fig. S1 in the Supplementary Appendix). If contact could not be made at the time of study termination, data were censored in the analysis at the time of the last contact.

\section{HEMOGLOBIN VALUES}

The median hemoglobin level at baseline was $11.2 \mathrm{~g}$ per deciliter in the two study groups (Table 1). On the basis of the area under the curve (AUC), the median attained hemoglobin level over time was $13.0 \mathrm{~g}$ per deciliter (interquartile range, 12.4 to 13.4 ) in the darbepoetin alfa group and $11.5 \mathrm{~g}$ per deciliter (interquartile range, 10.7 to 12.2) in the placebo group $(\mathrm{P}<0.001)$ (Fig. 1).

The between-group difference in the hemoglobin level was significant by 1 month after randomization and remained so throughout the study. In the 1122 patients in each study group who received a study drug and provided a post- baseline blood sample, the hemoglobin value was $13.0 \mathrm{~g}$ per deciliter or more on three consecutive occasions in 807 patients (71.9\%) in the darbepoetin alfa group and 241 (21.5\%) in the placebo group $(\mathrm{P}<0.001)$. The median monthly dose in the darbepoetin alfa group was $167 \mu \mathrm{g}$ (interquartile range, 105 to 286).

\section{ANEMIA TREATMENTS IN ADDITION TO THE STUDY DRUG}

A total of 40 patients $(3.5 \%)$ in the darbepoetin alfa group and $77(6.7 \%)$ in the placebo group received at least one dose of a nonstudy ESA $(\mathrm{P}<0.001)$. There was no significant difference in the proportion of patients who received iron at least once during the study (intravenous iron: $4.9 \%$ in the darbepoetin alfa group and $5.6 \%$ in the placebo group, $\mathrm{P}=0.47$; oral iron: $72.3 \%$ in the darbepoetin alfa group and $73.5 \%$ in the placebo group, $\mathrm{P}=0.52$ ). Among patients who received a study drug, one or more blood transfusions were performed in 123 patients (10.9\%) in the darbepoetin alfa group and in $188(16.5 \%)$ in the placebo group $(\mathrm{P}<0.001)$.

\section{STUDY OUTCOMES}

The primary composite outcome of death from any cause or first hospitalization for worsening heart failure occurred in 576 patients (50.7\%) in the darbepoetin alfa group and 565 (49.5\%) in the 


\begin{tabular}{|c|c|c|c|c|}
\hline Outcome & $\begin{array}{l}\text { Darbepoetin Alfa } \\
\quad(\mathrm{N}=1136)\end{array}$ & $\begin{array}{l}\text { Placebo } \\
(\mathrm{N}=1142)\end{array}$ & $\begin{array}{l}\text { Hazard Ratio } \\
(95 \% \mathrm{Cl}) *\end{array}$ & P Value' \\
\hline \multicolumn{5}{|c|}{ no. of patients (\%) } \\
\hline \multicolumn{5}{|l|}{ Primary composite outcome } \\
\hline $\begin{array}{l}\text { Death from any cause or first hospitalization for worsening } \\
\text { heart failure }\end{array}$ & $576(50.7)$ & $565(49.5)$ & $1.01(0.90-1.13)$ & 0.87 \\
\hline Death from any cause & $474(41.7)$ & $458(40.1)$ & $1.04(0.92-1.19)$ & 0.51 \\
\hline First hospitalization for worsening heart failure & $314(27.6)$ & $311(27.2)$ & $0.99(0.85-1.16)$ & 0.92 \\
\hline \multicolumn{5}{|l|}{ Secondary composite outcome } \\
\hline $\begin{array}{l}\text { Death from cardiovascular causes or first hospitalization for } \\
\text { worsening heart failure }\end{array}$ & $513(45.2)$ & $506(44.3)$ & $1.01(0.89-1.14)$ & 0.92 \\
\hline Death from cardiovascular causes & $388(34.2)$ & $376(32.9)$ & $1.04(0.91-1.20)$ & 0.56 \\
\hline \multicolumn{5}{|l|}{ Other adjudicated outcomes } \\
\hline Death from any cause or first nonfatal cardiovascular event & $607(53.4)$ & $589(51.6)$ & $1.04(0.93-1.17)$ & 0.49 \\
\hline Fatal or nonfatal myocardial infarction』 & $64(5.6)$ & $74(6.5)$ & $0.84(0.60-1.18)$ & 0.32 \\
\hline Unstable angina & $18(1.6)$ & $12(1.1)$ & $1.49(0.72-3.09)$ & 0.28 \\
\hline Fatal or nonfatal stroke & $42(3.7)$ & $31(2.7)$ & $1.33(0.83-2.12)$ & 0.23 \\
\hline Heart failure during ongoing hospitalization & $25(2.2)$ & $22(1.9)$ & $1.08(0.61-1.93)$ & 0.78 \\
\hline Deep venous thrombosis & $10(0.9)$ & $10(0.9)$ & $1.01(0.42-2.43)$ & 0.98 \\
\hline Fatal or nonfatal pulmonary embolism\| & $6(0.5)$ & $2(0.2)$ & $3.20(0.64-15.90)$ & 0.13 \\
\hline Resuscitation after cardiac arrest & $12(1.1)$ & $15(1.3)$ & $0.77(0.36-1.65)$ & 0.50 \\
\hline
\end{tabular}

placebo group (hazard ratio in the darbepoetin alfa group, 1.01; 95\% confidence interval [CI], 0.90 to $1.13 ; \mathrm{P}=0.87$ ) (Table 2 and Fig. 2A). The result of the analysis adjusted for baseline characteristics was similar (adjusted hazard ratio, 1.01; $95 \%$ CI, 0.90 to $1.13 ; \mathrm{P}=0.88$ ), as was the result of the as-treated analysis (hazard ratio, 0.98; 95\% CI, 0.86 to $1.13 ; \mathrm{P}=0.82$ ). The result for the primary outcome was consistent across all subgroups examined (Fig. S2 in the Supplementary Appendix).

There were 474 deaths $(41.7 \%)$ in the darbepoetin alfa group and $458(40.1 \%)$ in the placebo group (hazard ratio, 1.04; 95\% CI, 0.92 to 1.19; $\mathrm{P}=0.51$ ) (Table 2 and Fig. 2B), corresponding to overall annualized mortality rates of $14.4 \%$ and $13.8 \%$, respectively. The number of patients who died from cardiovascular causes or had a first hospitalization for worsening heart failure was similar in the two study groups, as was the number of patients for each of the components of this composite outcome (Table 2 and Fig. 2). The total numbers of hospitalizations for heart failure (including second and subsequent hospitalizations) were 572 in the darbepoetin alfa group and 695 in the placebo group $(\mathrm{P}=0.06$ from a negative binomial model).

Fatal or nonfatal adjudicated stroke occurred in 42 patients (3.7\%) in the darbepoetin alfa group and $31(2.7 \%)$ in the placebo group (hazard ratio, 1.33; $95 \% \mathrm{CI}, 0.83$ to $2.12 ; \mathrm{P}=0.23$ ). All other prespecified adjudicated outcomes are summarized in Table 2.

The least-squares mean changes from baseline to month 6 in the Overall Summary Score of the KCCQ were 6.68 points (95\% CI, 5.35 to 8.01) in the darbepoetin alfa group and 4.48 points $(95 \%$ CI, 3.15 to 5.81 ) in the placebo group (treatment 


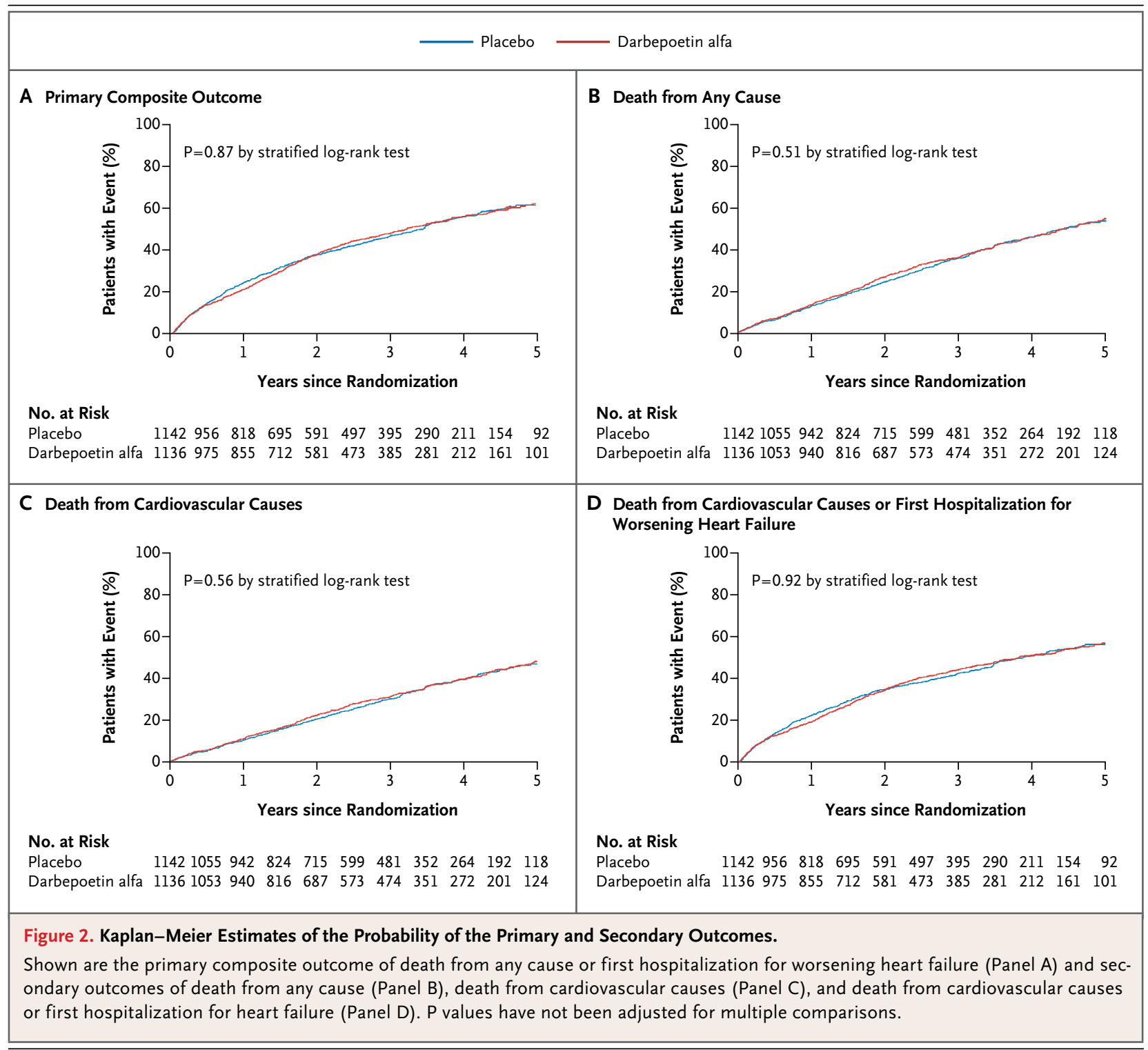

difference, 2.20 points; $95 \%$ CI, 0.65 to 3.75 ; $\mathrm{P}=0.005$ ). The proportions of patients with an improvement in the Overall Summary Score of 5 points or more at 6 months were $53 \%$ in the darbepoetin alfa group and $48 \%$ in the placebo group $(\mathrm{P}=0.06)$. The increases from baseline to 6 months in the Symptom Frequency Score were 6.20 points ( $95 \% \mathrm{CI}, 4.71$ to 7.69 ) in the darbepoetin alfa group and 3.91 points $(95 \%$ CI, 2.42 to $5.40)$ in the placebo group $(\mathrm{P}=0.01)$.

\section{ADVERSE EVENTS}

In the darbepoetin alfa group, 221 of 1133 patients (19.5\%) had an adverse event leading to study- drug discontinuation, as compared with 229 of $1140(20.1 \%)$ in the placebo group $(\mathrm{P}=0.73)$. The most frequent serious adverse events, and those of particular interest, are summarized in Table 3 and in more detail in Table S5 in the Supplementary Appendix. Embolic and thrombotic adverse events were reported in 153 patients (13.5\%) in the darbepoetin alfa group and $114(10.0 \%)$ in the placebo group ( $\mathrm{P}=0.01$ ) (Table 3, and Table S6 in the Supplementary Appendix). With respect to serious adverse events, septic shock was reported significantly more frequently in the darbepoetin alfa group than in the placebo group, although there was no excess of other serious adverse events 


\begin{tabular}{|c|c|c|c|c|}
\hline \multirow[t]{2}{*}{ Adverse Event } & $\begin{array}{l}\text { Darbepoetin Alfa } \\
\qquad(\mathrm{N}=1133)\end{array}$ & $\begin{array}{l}\text { Placebo } \\
(\mathrm{N}=1140)\end{array}$ & $\begin{array}{l}\text { Risk Difference } \\
\qquad(95 \% \mathrm{Cl}) 广\end{array}$ & P Value \\
\hline & \multicolumn{2}{|c|}{ no. of patients (\%) } & percentage points & \\
\hline Any event of interest & $660(58.3)$ & $662(58.1)$ & $0.2(-3.9$ to 4.2$)$ & 0.93 \\
\hline Cardiac failure & $438(38.7)$ & $459(40.3)$ & $-1.6(-5.6$ to 2.4$)$ & 0.43 \\
\hline Ischemic heart disease & $155(13.7)$ & $164(14.4)$ & $-0.7(-3.6$ to 2.2$)$ & 0.63 \\
\hline \multicolumn{5}{|l|}{ Cerebrovascular disorder } \\
\hline Any & $61(5.4)$ & $45(3.9)$ & $1.4(-0.3$ to 3.2$)$ & 0.10 \\
\hline Hemorrhagic & $39(3.4)$ & $30(2.6)$ & $0.8(-0.6$ to 2.2$)$ & 0.26 \\
\hline Ischemic & $51(4.5)$ & $32(2.8)$ & $1.7(0.2$ to 3.2$)$ & 0.03 \\
\hline \multicolumn{5}{|l|}{ Embolic and thrombotic events } \\
\hline Any & $153(13.5)$ & $114(10.0)$ & $3.5(0.9$ to 6.1$)$ & 0.009 \\
\hline Arterial $\sqrt{ }$ & $87(7.7)$ & $73(6.4)$ & $1.3(-0.8$ to 3.4$)$ & 0.24 \\
\hline Venous $\emptyset$ & $29(2.6)$ & $20(1.8)$ & $0.8(-0.4$ to 2.0$)$ & 0.19 \\
\hline $\begin{array}{l}\text { Vessel type unspecified and mixed arterial } \\
\text { and venous } \|\end{array}$ & $51(4.5)$ & $27(2.4)$ & 2.1 (0.6 to 3.6$)$ & 0.005 \\
\hline Hemodialysis-related vascular access thrombosis & $1(0.1)$ & 0 & $0.1(-0.1$ to 0.3$)$ & 0.50 \\
\hline Hypertension & $81(7.1)$ & $69(6.1)$ & $1.1(-0.9$ to 3.1$)$ & 0.29 \\
\hline Cancer & $69(6.1)$ & $68(6.0)$ & 0.1 (-1.8 to 2.1$)$ & 0.90 \\
\hline Convulsions & $4(0.4)$ & $5(0.4)$ & $-0.1(-0.6$ to 0.4$)$ & 1.00 \\
\hline Hypersensitivity reactions & $99(8.7)$ & $96(8.4)$ & $0.3(-2.0$ to 2.6$)$ & 0.79 \\
\hline Antibody-mediated pure red-cell aplasia & 0 & 0 & NA & NA \\
\hline \multicolumn{5}{|c|}{$\begin{array}{l}\text { Adverse events of interest were identified with the use of the prespecified Standard MedDRA (Medical Dictionary for } \\
\text { Regulatory Activities) Query (SMQ) search strategies, as specified in the statistical analysis plan. Patients could have } \\
\text { more than one event in each overall category. Data are for patients who received at least one dose of a study drug. NA } \\
\text { denotes not applicable. } \\
\text { The risk difference for each event was calculated as the percentage of patients with the event in the darbepoetin alfa group } \\
\text { minus the percentage of patients with the event in the placebo group. The } 95 \% \text { Wald asymptotic confidence intervals } \\
\text { for the risk difference were calculated. } \\
\text { P values were calculated with the use of Pearson's chi-square test, except for hemodialysis-related vascular access } \\
\text { thrombosis and convulsions, for which Fisher's exact test was used. P values have not been adjusted for multiple com- } \\
\text { parisons. } \\
\text { Included in the arterial-events category are the following preferred terms: acute myocardial infarction, amaurosis fugax, } \\
\text { carotid-artery occlusion, cerebrovascular insufficiency, coronary arterial stent insertion, coronary-artery occlusion, ischemic } \\
\text { stroke, lacunar infarction, myocardial infarction, percutaneous coronary intervention, peripheral arterial occlusive disease, } \\
\text { peripheral-artery thrombosis, peripheral embolism, retinal-artery occlusion, and transient ischemic attack. } \\
\text { Included in the venous-events category are the following preferred terms: deep-vein thrombosis, jugular-vein thrombosis, } \\
\text { pulmonary embolism, retinal-vein occlusion, thrombophlebitis, superficial thrombophlebitis, and limb venous thrombosis } \\
\text { Included in the unspecified events are the following preferred terms: bone infarction, cerebral infarction, cerebral isch- } \\
\text { emia, cerebrovascular accident, coronary-artery thrombosis, embolism, hemorrhagic stroke, hemiparesis, hemiplegia, } \\
\text { heparin-induced thrombocytopenia, intestinal infarction, intracardiac thrombus, shunt occlusion, splenic infarction, } \\
\text { thrombosis, thrombosis in device, mesenteric-vessel thrombosis, and thrombosis prophylaxis. }\end{array}$} \\
\hline
\end{tabular}

related to infection in the darbepoetin alfa group (Table S7 in the Supplementary Appendix). A history of cancer at baseline was reported by 93 patients in the darbepoetin alfa group and 78 in the placebo group. Of these patients, 44 in the darbepoetin alfa group and 36 in the placebo group died; the deaths were attributed to cancer in 4 and
6 of the patients, respectively, with no significant between-group differences. There was no significant between-group difference in systolic blood pressure during the study, but the diastolic blood pressure was $1 \mathrm{~mm}$ Hg higher (median AUC) in the darbepoetin alfa group than in the placebo group $(\mathrm{P}=0.03)$. 


\section{I SCUSSION}

We evaluated the effect of correcting anemia in patients with systolic heart failure by adding darbepoetin alfa to contemporary therapy, with a target hemoglobin level of $13.0 \mathrm{~g}$ per deciliter. As compared with placebo, darbepoetin alfa treatment led to an early and sustained increase in the hemoglobin level. Despite this improvement, the use of darbepoetin alfa did not reduce the risk of the primary outcome of death or hospitalization for worsening heart failure. None of the other adjudicated outcomes differed significantly between the two study groups. The lack of effect of darbepoetin alfa was consistent across all prespecified subgroups.

From a safety perspective, more patients had fatal or nonfatal strokes in the darbepoetin alfa group than in the placebo group. Although the difference was not significant, this observation is in keeping with the findings of the Trial to Reduce Cardiovascular Events with Aranesp Therapy (TREAT), ${ }^{16}$ a study of darbepoetin alfa in patients with diabetes, chronic kidney disease, and anemia. As has been noted in other populations, ${ }^{17,18}$ there was a significant increase in investigatorreported arterial and venous thromboembolic events in patients receiving darbepoetin alfa.

Although the rate of clinical events was not reduced in the darbepoetin alfa group, treatment of anemia did improve the Overall Summary and Symptom Frequency Scores on the KCCQ. However, the average between-group difference and the difference in the proportion of patients with a clinically meaningful improvement in these scores were of questionable importance.

Although we enrolled patients with mild-tomoderate anemia, they were at high risk for events, and we accrued the number of primary outcome events that were needed to test our hypothesis. Our patients were iron-replete at baseline, had a high use of iron during the study (as dictated by the study protocol), and did not become iron-deficient during the study. The protocol-defined hemoglobin target of $13.0 \mathrm{~g}$ per deciliter was attained in the darbepoetin alfa group, and the median betweengroup difference in the hemoglobin level was $1.5 \mathrm{~g}$ per deciliter (since there was a slight increase in hemoglobin level in the placebo group). Observational studies have shown that outcomes are worse in patients with heart failure who have a hemoglobin level of less than $12.0 \mathrm{~g}$ per deciliter than in those with a hemoglobin level of $12.0 \mathrm{~g}$ per deciliter or more. ${ }^{2,23}$ Moreover, in these studies, a change of $1 \mathrm{~g}$ per deciliter was associated with a difference in all-cause mortality of approximately 15 to 20 percentage points (and a similar difference in a composite of all-cause mortality or heartfailure hospitalization). ${ }^{23}$ Consequently, our findings suggest that the hemoglobin level, like other surrogates, is simply a marker of poor prognosis in heart failure rather than a therapeutic target.

A limitation of our study is that we excluded patients with severe anemia (hemoglobin level, $<9.0$ g per deciliter). Such patients might have a greater increase in hemoglobin values with darbepoetin alfa (with greater separation from the findings in the placebo group). However, severe anemia is uncommon in patients with heart failure. Also, we tested one approach to elevating the hemoglobin level, and other strategies may have different effects.

In summary, we found that the correction of anemia with the use of darbepoetin alfa did not reduce the rate of death or hospitalization among patients with systolic heart failure who were receiving contemporary treatment. Moreover, there was a significant increase in the risk of thromboembolic events among patients receiving darbepoetin alfa. Our findings do not support the use of darbepoetin alfa in patients with systolic heart failure and mild-to-moderate anemia.

Supported by Amgen.

Disclosure forms provided by the authors are available with the full text of this article at NEJM.org.

REFERENCES

1. O'Meara E, Murphy C, McMurray JJ. Anemia and heart failure. Curr Heart Fail Rep 2004;1:176-82.

2. Anand I, McMurray JJ, Whitmore J, et al. Anemia and its relationship to clinical outcome in heart failure. Circulation 2004;110:149-54.

3. Maggioni AP, Opasich C, Anand I, et al. Anemia in patients with heart failure: prevalence and prognostic role in a controlled trial and in clinical practice. J Card Fail 2005;11:91-8.

4. O'Meara E, Clayton T, McEntegart MB, et al. Clinical correlates and consequences of anemia in a broad spectrum of patients with heart failure: results of the Candesar- tan in Heart Failure: Assessment of Reduction in Mortality and Morbidity (CHARM) Program. Circulation 2006;113:986-94.

5. Komajda M, Anker SD, Charlesworth A, et al. The impact of new onset anaemia on morbidity and mortality in chronic heart failure: results from COMET. Eur Heart J 2006;27:1440-6. 
6. Anand IS. Pathophysiology of anemia in heart failure. Heart Fail Clin 2010;6: 279-88.

7. Westenbrink BD, Voors AA, de Boer $\mathrm{RA}$, et al. Bone marrow dysfunction in chronic heart failure patients. Eur J Heart Fail 2010;12:676-84.

8. Silverberg DS, Wexler D, Sheps D, et al. The effect of correction of mild anemia in severe, resistant congestive heart failure using subcutaneous erythropoietin and intravenous iron: a randomized controlled study. J Am Coll Cardiol 2001;37:1775-80. 9. Cleland JG, Sullivan JT, Ball S, et al. Once-monthly administration of darbepoetin alfa for the treatment of patients with chronic heart failure and anemia: a pharmacokinetic and pharmacodynamic investigation. J Cardiovasc Pharmacol 2005;46:155-61.

10. Ngo K, Kotecha D, Walters JA, et al. Erythropoiesis-stimulating agents for anaemia in chronic heart failure patients. Cochrane Database Syst Rev 2010;1: CD007613.

11. Ghali JK, Anand IS, Abraham WT, et al. Randomized double-blind trial of darbepoetin alfa in patients with symptomatic heart failure and anemia. Circulation 2008;117:526-35.

12. Ponikowski P, Anker SD, Szachniewicz J, et al. Effect of darbepoetin alfa on exercise tolerance in anemic patients with symptomatic chronic heart failure: a randomized, double-blind, placebo-controlled trial. J Am Coll Cardiol 2007;49:753-62.

13. van Veldhuisen DJ, Dickstein K, CohenSolal A, et al. Randomized, double-blind, placebo-controlled study to evaluate the effect of two dosing regimens of darbepoetin alfa in patients with heart failure and anaemia. Eur Heart J 2007;28:2208-16.

14. Klapholz M, Abraham WT, Ghali JK, et al. The safety and tolerability of darbepoetin alfa in patients with anaemia and symptomatic heart failure. Eur J Heart Fail 2009;11:1071-7.

15. van der Meer P, Groenveld HF, Januzzi JL Jr, van Veldhuisen DJ. Erythropoietin treatment in patients with chronic heart failure: a meta-analysis. Heart 2009;95: 1309-14.

16. Pfeffer MA, Burdmann EA, Chen C-Y, et al. A trial of darbepoetin alfa in type 2 diabetes and chronic kidney disease. N Engl J Med 2009;361:2019-32.

17. Singh AK, Szczech L, Tang KL, et al. Correction of anemia with epoetin alfa in chronic kidney disease. $\mathrm{N}$ Engl J Med 2006;355:2085-98.

18. Besarab A, Bolton WK, Browne JK, et al. The effects of normal as compared with low hematocrit values in patients with cardiac disease who are receiving hemodialysis and epoetin. N Engl J Med 1998;339:584-90.
19. McMurray JJ, Anand IS, Diaz R, et al. Design of the Reduction of Events with Darbepoetin Alfa in Heart Failure (REDHF): a phase III, anaemia correction, morbidity-mortality trial. Eur J Heart Fail 2009;11:795-801. [Erratum, Eur J Heart Fail 2010;12:765.]

20. Green CP, Porter CB, Bresnahan DR, Spertus JA. Development and evaluation of the Kansas City Cardiomyopathy Questionnaire: a new health status measure for heart failure. J Am Coll Cardiol 2000; 35:1245-55.

21. Pettersen KI, Reikvam A, Rollag A, Stavem K. Reliability and validity of the Kansas City cardiomyopathy questionnaire in patients with previous myocardial infarction. Eur J Heart Fail 2005;7:235-42. 22. McMurray JJV, Anand IA, Diaz R, et al. Baseline characteristics of patients in the Reduction of Events with Darbepoetin Alfa in Heart Failure trial (RED-HF). Eur J Heart Fail 2013;15:334-41.

23. Anand IS, Kuskowski MA, Rector TS, et al. Anemia and change in hemoglobin over time related to mortality and morbidity in patients with chronic heart failure: results from Val-HeFT. Circulation 2005;112:1121-7.

Copyright (c) 2013 Massachusetts Medical Society. 